\title{
Endoscopy-related musculoskeletal injuries in gastroenterology fellows
}

\section{다)(우 $\odot$}

\author{
Authors \\ Edward Villa', Bashar Attar ${ }^{1}$, William Trick², Vikram Kotwal ${ }^{1}$
}

Institutions

1 John H Stroger Jr. Hospital of Cook County, Division of Gastroenterology and Hepatology, Chicago, Illinois, United States

2 John H Stroger Jr. Hospital of Cook County, Division of Internal Medicine, Chicago, Illinois, United Staes

submitted 28.4.2018

accepted after revision 21.11.2018

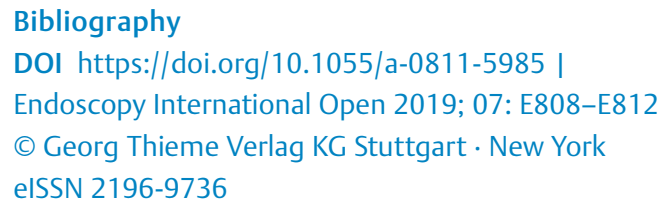

\section{ABSTRACT}

Background and study aims Gastroenterologists are at high risk for work-related musculoskeletal injuries. Studies have shown that $37 \%$ to $89 \%$ of endoscopists have workrelated musculoskeletal injuries. While all surveys until now have focused on practicing endoscopists, there have been no publications assessing the prevalence of musculoskeletal injuries among gastrointerology fellows, which we sought to investigate.

Methods A 22-question survey about ergonomics and work-related musculoskeletal injuries was sent to 114 gastroenterology fellows in different programs across the United States in June 2016, and an additional 103 surveys were distributed at Digestive Disease Week in May 2017. Responses were collected, and data were analyzed.

Results A total of 156 surveys were collected. Of these, 74 fellows ( $47 \%$ ) reported a new musculoskeletal injury related to endoscopy. Injuries occurred mostly in the first year of fellowship ( $85 \%, P<0.001)$. The most common sites of injury were the right wrist (53\%), left thumb (42\%), back (27\%), and neck (22\%). Only $26 \%$ those who had endoscopy-related musculoskeletal injuries had received training in ergonomics compared to $45 \%$ of those who did not have injury $(P=0.012)$, and ergonomics training was highly desirable among respondents, particularly among those with previous injuries $(P=0.0030)$

Conclusion Musculoskeletal injuries related to endoscopy are very common among gastroenterology fellows, particularly during the first year of fellowship. While the overall percentage of fellows who received training in ergonomics was low, those who did receive training were less like to report a musculoskeletal injury. There is an urgent need for ergonomics training among Gastroenterology fellows.

\section{Introduction}

Musculoskeletal disorders account for nearly 70 million physician office visits in the United States annually, and an estimated 130 million total health care encounters, including outpatient, emergency department, and inpatient visits. The Institute of Medicine estimates of the economic burden of work-related musculoskeletal disorders (WMSDs) - as measured by compensation costs, lost wages, and lost productivity - are between $\$ 45$ billion and $\$ 54$ billion annually [1]. In addition to economic loss, these disorders also lead to decreased quality of life. Those working in nursing and healthcare facilities are especially prone to WMSDs [1]. Among physicians, endoscopists are at increased risk for WMSDs compared to internists and other specialists who are not procedure-oriented with $37 \%$ to $89 \%$ of endoscopists reporting musculoskeletal injuries [2,3].

Several factors influence endoscopy-related musculoskeletal pain. The most commonly reported factor is high procedure volume and prolonged duration of performing endoscopy, which leads to overuse injury from repetitive movements [46]. Other risk factors that have been reported are improper position during performing endoscopy and endoscopy-specific maneuvers like torqueing during colonoscopy and use of control dials [5,7-9]. These maneuvers lead to certain endoscopy-specific injuries, such as “Colonoscopist's Thumb," or De- 
Quervain's tenosynovitis $[10,11]$. Other common sites of injuries in endoscopists are the neck, back, shoulder and elbow [6].

While the data alarmingly reveal the problems facing endoscopists in practice, little is known about musculoskeletal injuries among gastroenterology fellows. Because of the implications of musculoskeletal injuries and the potential for permanent injury, we sought to assess the prevalence of injuries among fellows to open future investigations into ergonomicspecific education that can reduce injuries.

\section{Methods}

A 22-question survey about ergonomics and work-related musculoskeletal injuries was developed (see supplemental appendix). As there were no individual identifiers in the survey questions, the Institutional Review Board exempted it. An email with an invitation to participate in the survey was sent to 114 gastroenterology fellows in different programs across the United States in June 2016 (these were sent by the authors through their contacts in different programs). The invitation email had a web link to the survey instrument (Survey Monkey, Palo Alto, California, United States). Fellows who did not respond within a week were sent a second reminder email. Responses were collected, and the data were analyzed. An additional 103 paper surveys were distributed at Digestive Disease Week (DDW) in May of 2017 to fellows who confirmed that they had not responded to the online survey, and the data were added to the previously collected online surveys for analysis. No monetary compensation was given for participation in the survey.

\section{Statistical analysis}

We used descriptive statistics to define the prevalence of injuries related to endoscopy. Responders were classified into two main groups: those reporting no new injury during fellowship and those reporting a new musculoskeletal injury during fellowship which was attributable to performing endoscopy. We then applied the Pearson chi-squared analysis to assess the statistical differences between these groups. Differences across groups were considered significant if the associated $P$ value was less than 0.05 .

\section{Results}

Fifty-three out of 114 fellows (46\%) responded to the online survey, and all 103 surveys distributed at DDW were collected. The respondents were equally distributed across the 3 years of their fellowship training ( $\triangleright$ Table $1, P=0.98$ ). Of 156 respondents, 87 (56\%) reported at least one new musculoskeletal injury sustained since the start of fellowship. Of the 87 gastroenterology fellows who reported new injuries experienced during fellowship, 74 (47\% overall) reported that these injuries were related to endoscopy ( $\triangleright$ Table 1 ). When compared to those without endoscopy-related injury, those with endoscopy-related musculoskeletal injury were similar in age $(P=0.75)$, gender (56\% of females sustained injury compared to $42 \%$ of males, $P=$ $0.10)$, and training in endoscopic retrograde cholangiopancreatography $(\mathrm{ERCP})(27 \%$ vs $28 \%, P=0.89)$ ( $\triangleright$ Table 1$)$. There was no significant difference between the groups when we compared the online respondents to those who took the paper survey.

Sixty-three ( $85 \%$ ) reported that the new injury(ies) occurred during the first year of fellowship ( $\triangleright$ Table 1 ). The respondents cited multiple injuries sustained, including the right wrist (53\%), left thumb (48\%), back (31\%), neck (22\%), among others ( $\triangleright$ Fig. 1). Of the 74 fellows reporting an endoscopy-related injury, only three (4\%) reported that time was missed due to that injury, but the time missed did not exceed 3 days ( $\triangleright$ Table 2 ). While 35 fellows (47\%) took pain medications, only one (1\%) saw a specialist for the injury sustained ( $\triangleright$ Table 2 ).

Of the 74 fellows who reported at least one injury related to endoscopy, only 19 (26\%) had received ergonomics training during fellowship, whereas 37 of the 82 who did not report endoscopy-related injury (45\%) had received ergonomics training ( $\triangleright$ Table 1$)$, which was a statistically significant difference $(P<0.001) .63(85 \%)$ of those sustaining endoscopy-related injuries and $104(67 \%)$ of overall respondents stated that they were interested in receiving ergonomics training ( $\triangleright$ Table 1$)$.

\section{Discussion}

Endoscopists are at increased risk of musculoskeletal injuries. Published data have focused on the prevalence of musculoskeletal injuries and assessing the role of ergonomics among practicing gastroenterologists. As many as $39 \%$ to $89 \%$ overall prevalence of pain or musculoskeletal injuries is reported among reporting endoscopists $[2,3,11,12]$. However, prior to our study, prevalence of musculoskeletal injuries among gastroenterology fellows had not been reported. The results of our study reveal that among the responders, an alarming $47 \%$ of fellows admitted to at least one new endoscopy-related musculoskeletal injury sustained during fellowship, most of which (85\%) occurred during the first 12 months of gastroenterology fellowship, arguably the most crucial period for learning proper techniques.

While factors influencing the development of injuries were not directly assessed in this study, based on previously published data, several factors influence endoscopy-related musculoskeletal pain. The most important factors are overuse and repetitive movements along with prolonged standing, all of which are integral parts of performing endoscopy. Previous studies have shown that performing endoscopy for more than 16 hours per week (or 20 cases) increases risk of musculoskeletal injuries $[6,12]$. A considerable proportion of fellows easily exceed this threshold. This is more relevant for fellowships emphasizing clinical and procedural training with high procedural volumes rather than fellowships with more of a research focus. While there are regulations regarding work hours for house staff, including fellows, there are no procedural limitations placed by the Accreditation Council for Graduate Medical Education for gastroenterology fellows. We believe this to be an important issue worth addressing by the gastroenterology societies.

Other factors leading to injuries are improper positioning of the patient and monitor (height of the bed being too low or too high and monitor not being right in front of the endoscopist 
- Table 1 Demographic data from respondents.

\section{Endoscopy-related MSK injury}

\begin{tabular}{|l|l|l|}
\hline $\begin{array}{l}\text { Yes } \\
\text { (total=74) }\end{array}$ & $\begin{array}{l}\text { No } \\
\text { (total=82) }\end{array}$ & Total (\%) \\
\hline
\end{tabular}

Age

\begin{tabular}{|l}
\hline Age \\
\hline \\
\hline \\
\hline Gender $(P=0.10)$ \\
\hline
\end{tabular}

\begin{tabular}{|l|r|}
\hline 25 to 30 & 9 \\
\hline 31 to 35 & 48 \\
\hline 36 to 40 & 16 \\
\hline 41 or older & 1 \\
\hline
\end{tabular}

Ethnicity $(P=0.79)$

Female

Asian/Indian
White/Caucasian
Hispanic/Latino
Black/African American
Other

\begin{tabular}{|l|}
\hline 31 \\
\hline 43 \\
\hline 39 \\
\hline 23 \\
\hline 6 \\
\hline 5 \\
\hline 1 \\
\hline
\end{tabular}

\begin{tabular}{|l|l|}
\hline 15 & 24 \\
\hline 51 & 99 \\
\hline 15 & 31 \\
\hline 1 & 2 \\
\hline
\end{tabular}
$X^{2}=1.22$

\begin{tabular}{|r|r|l|}
\hline 24 & 55 & $X^{2}=2.72$ \\
\hline 58 & 101 & $P=0.10$ \\
\hline
\end{tabular}

\begin{tabular}{|l|}
\hline \\
\hline Year in Fellowship at time of response $(P=0.98)$ \\
\hline
\end{tabular}

\begin{tabular}{|c|c|c|c|c|}
\hline 1st year & 25 & 26 & 51 & \multirow{4}{*}{$\begin{array}{l}X^{2}=0.16 \\
P=0.98\end{array}$} \\
\hline 2 nd year & 24 & 26 & 50 & \\
\hline 3 rd year & 24 & 29 & 53 & \\
\hline Other & 1 & 1 & 2 & \\
\hline
\end{tabular}

Timing of endoscopy-related injury

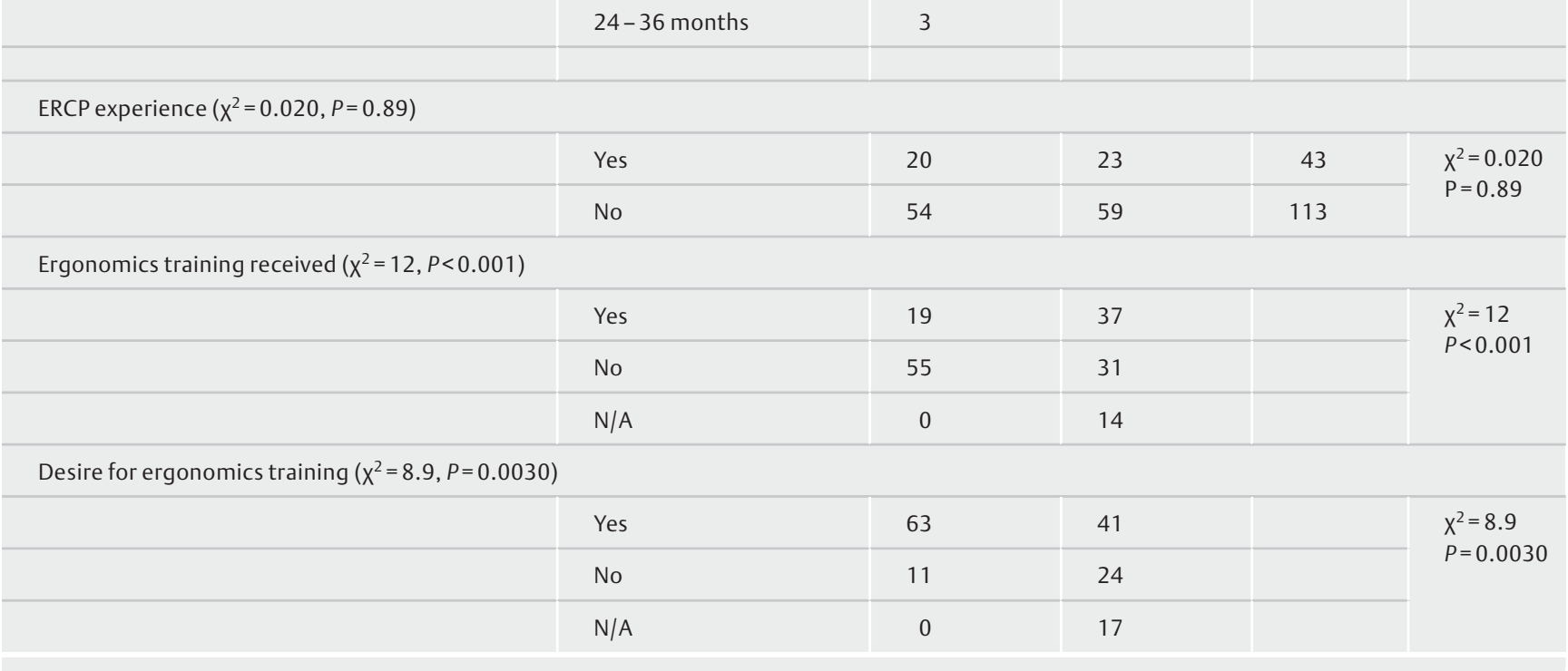

MSK, musculoskeletal injury; ERCP, endoscopic retrograde cholangiopancreatography

\begin{tabular}{|l|r|}
\hline $0-3$ months & 23 \\
\hline $3-6$ months & 28 \\
\hline $6-12$ months & 13 \\
\hline $12-24$ months & 7 \\
\hline $24-36$ months & 3 \\
\hline
\end{tabular}

\begin{tabular}{|c|c|c|}
\hline 44 & 83 & \multirow{5}{*}{$\begin{array}{l}X^{2}=1.73 \\
P=0.79\end{array}$} \\
\hline 27 & 50 & \\
\hline 4 & 10 & \\
\hline 4 & 9 & \\
\hline 3 & 4 & \\
\hline
\end{tabular}




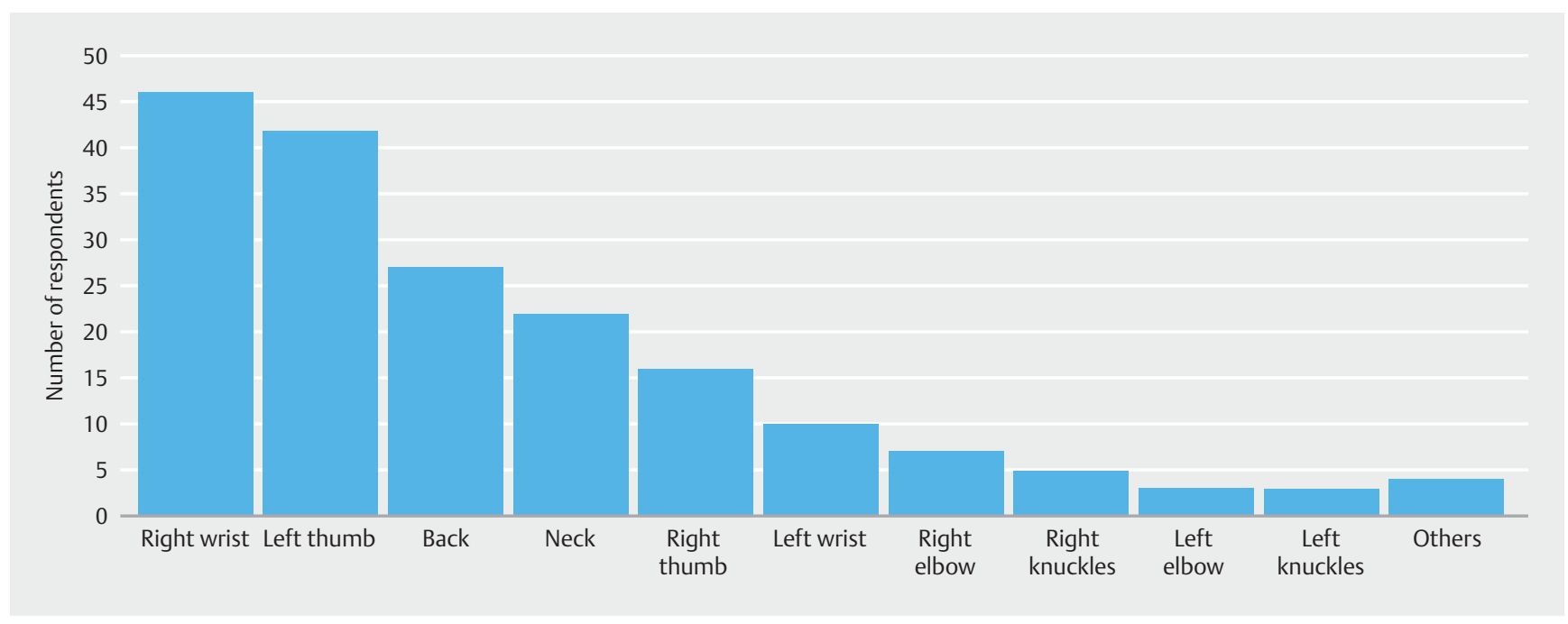

- Fig. 1 Site of endoscopy-related musculoskeletal injury.

- Table 2 Consequences of endoscopy-related musculoskeletal injuries.

\begin{tabular}{|l|l|r|}
\hline Time missed due to injury & \multicolumn{2}{|c|}{} \\
\hline & $1-3$ days & 3 \\
\hline NSAID use for injury & None & 71 \\
\hline & & 35 \\
\hline & Yes & 36 \\
\hline & No & 3 \\
\hline
\end{tabular}

\begin{tabular}{|l|l|r|}
\hline Other treatments for pain & \multicolumn{2}{|c|}{} \\
\hline & Yes & 3 \\
\hline - Splint & 2 \\
\hline - Other & 1 \\
\hline No & 68 \\
\hline No response & 3 \\
\hline
\end{tabular}

\begin{tabular}{|l|r|r|}
\hline Saw specialist due to injury & \multicolumn{1}{|c|}{} \\
\hline & Yes & 69 \\
\hline No & 4 \\
\hline
\end{tabular}

\begin{tabular}{|l|r|r|}
\hline Modified endoscopy technique & \multicolumn{1}{|l|}{} \\
\hline & Yes & 48 \\
\hline No & 23 \\
\hline No response & 3 \\
\hline
\end{tabular}

NSAID, nonsteroidal anti-inflammatory drug and just below eye level) or improper technique, such as excessive torqueing and high pinch forces $[3,11,12]$. To avoid improper positioning, endoscopy units should consider having an "Ergonomic Timeout" prior to starting procedures to ensure proper bed height, patient position, and monitor location. To avoid improper technique, it is crucial that fellows are monitored closely and informed about these errors early during fellowship before adopting improper techniques. This is especially important given that most first-time injuries occur during the first year of fellowship.

Because there are published studies that demonstrated an increase in reported musculoskeletal injuries among gastroenterologists who practice ERCP [13], we sought to investigate whether there was similarly increased reporting of musculoskeletal injuries among gastroenterology fellows who performed ERCP during their fellowship; however, there was no statistically significant reporting of musculoskeletal injuries in those who were ERCP trained ( $\triangleright$ Table 2 ). This was possibly due to the fact that the majority of gastroenterology fellows in the United States do not have ERCP experience; that those who have ERCP experience do not have a significant case volume to experience musculoskeletal injuries; and/or that advanced or repetitive maneuvers that could lead to injuries were limited in inexperienced general gastroenterology fellows given the likelihood that attendings would take over a difficult case that would require such maneuvers.

Not surprisingly, our study demonstrated that those who reported no injuries had a statistically significantly higher reporting of ergonomics training than those who reported injuries. The lack of endoscopy-specific ergonomics education is believed to play a significant role in the overall poor compliance among endoscopists with regard to ergonomic practices [14], and our study demonstrates a willingness among the majority of fellows ( $67 \%$ of all responders) to address this issue by receiving ergonomics training. As such, we believe there is a need to train the instructors in applying endoscopic-specific ergonomic principles to their education of fellows and that there 
is a clear role for widespread education and implementation of guidelines for best clinical practice of ergonomics [3,14-16]. Based on our study, that training should begin at the start of fellowship.

There are certain drawbacks of our study. First, inherent to any survey is the possibility of "recall bias" among the respondents. Second, two different methods were used for data collection (survey by email and paper survey at DDW). However, we found similar results in respondents of both methods of survey. Third, our study did not assess the impact of fellows' procedure volumes and musculoskeletal injuries; given that the respondents were from many different fellowship programs with varying procedure scheduled. Finally, our sample size is small, and we were unable to determine whether specific types of injuries were more common during different years of fellowship and which specific injuries could be prevented by training in ergonomics.

The findings of our study suggest that musculoskeletal injuries may originate as early as fellowship (especially during the first year of fellowship) and there is a need for early ergonomics training. However, further studies are needed to assess the role of ergonomics training in decreasing work-related injuries; in affecting short-term and long-term disability; in impacting procedural efficiency and productivity; and in improving quality of life for endoscopists.

\section{Competing interests}

None

References

[1] Centers for Disease Control and Prevention (2016). Work-Related Musculoskeletal Disorders \& Ergonomics. Available from: https:// www.cdc.gov/workplacehealthpromotion/health-strategies/musculoskeletal-disorders
[2] Hansel SL, Crowell MD, Pardi DS et al. Prevalence and impact of musculoskeletal injury among endoscopists: a controlled pilot study. J Clin Gastroenterol 2009; 43: 399-404

[3] Shergill AK, McQuaid KR, Rempel D. Ergonomics and Gl endoscopy. Gastrointest Endosc 2009; 70: 145-153

[4] Buschbacher R. Overuse syndromes among endoscopists. Endoscopy 1994; 26: $539-544$

[5] Liberman AS, Shrier I, Gordon PH. Injuries sustained by colorectal surgeons performing colonoscopy. Surg Endosc 2005; 19: 1606 1609

[6] Ridtitid W, Cote GA, Leung W et al. Prevalence and risk factors for musculoskeletal injuries related to endoscopy. Gastrointest Endosc 2015; 81: 294-302 e4

[7] Byun YH, Lee JH, Park MK et al. Procedure-related musculoskeletal symptoms in gastrointestinal endoscopists in Korea. World J Gastroenterol 2008; 14: 4359-4364

[8] Kuwabara T, Urabe Y, Hiyama T et al. Prevalence and impact of musculoskeletal pain in Japanese gastrointestinal endoscopists: a controlled study. World J Gastroenterol 2011; 17: 1488-1493

[9] Shergill AK, Asundi KR, Barr A et al. Pinch force and forearm-muscle load during routine colonoscopy: a pilot study. Gastrointest Endosc 2009; 69: $142-146$

[10] Cappell MS. Colonoscopist's thumb: DeQuervains's syndrome (tenosynovitis of the left thumb) associated with overuse during endoscopy. Gastrointest Endosc 2006; 64: 841 - 843

[11] Harvin G. Review of musculoskeletal injuries and prevention in the endoscopy practitioner. J Clin Gastroenterol 2014; 48: 590 - 594

[12] Singla M, Kwok R, Deriban G et al. Training the endo-athlete: An update in ergonomics in endoscopy. Clin Gastro and Hepatol 2018; 16: $1003-1006$

[13] O'Sullivan S, Bridge P, Ponich T. Musculoskeletal injuries among ERCP endoscopists in Canada. Can J Gastroenterol 2002; 16: 369-374

[14] Edelman K, Zheng J, Erdmann A et al. Endoscopy-related musculoskeletal injury in AGA gastroenterologists is common while training in ergonomics is rare. Gastroenterol 2017; 152: S217

[15] Chang M, Mitchell J, Abbas Fehmi S. Optimizing ergonomics before endoscopy. Video GIE 2017; 2: 169

[16] Chang M, Mitchell J, Abbas Fehmi S. Optimizing ergonomics during endoscopy. Video GIE 2017; 2: 170 